\title{
Rumen protozoa and methanogenesis: not a simple cause-effect relationship
}

\author{
Diego P. Morgavi ${ }^{1 *}$, Cécile Martin ${ }^{1}$, Jean-Pierre Jouany ${ }^{1}$ and Maria José Ranilla ${ }^{2}$ \\ ${ }^{1}$ INRA, UR1213 Herbivores, Site de Theix, F-63122 St-Genès-Champanelle, France \\ ${ }^{2}$ Departamento de Producción Animal, Universidad de León, 24071 León, Spain
}

(Received 25 November 2010 - Revised 26 April 2011 - Accepted 27 April 2011 - First published online 18 July 2011)

\begin{abstract}
Understanding the interactions between hydrogen producers and consumers in the rumen ecosystem is important for ruminant production and methane mitigation. The present study explored the relationships between rumen protozoa, methanogens and fermentation characteristics. A total of six donor sheep harbouring (F, faunated) or not (D, defaunated) protozoa in their rumens (D animals were kept without protozoa for a period of a few months $(\mathrm{D}-)$ or for more than 2 years $(\mathrm{D}+)$ ) were used in in vitro and in vivo experiments. In vitro the absence of protozoa decreased $\mathrm{NH}_{3}$ and butyrate production and had no effect on methane. In contrast, the liquid-associated bacterial and methanogens fraction of $\mathrm{D}+$ inocula produced more methane than $\mathrm{D}-$ and $\mathrm{F}$ inoculum $(P<0 \cdot 05)$. In vivo fermentation parameters of donor animals showed the same trend on $\mathrm{NH}_{3}$ and butyrate and showed that $\mathrm{D}+$ animals were high methane emitters, while $\mathrm{D}-$ were the lowest $(-35 \%)$. The concentration of dissolved dihydrogen measured after feeding followed the opposite trend. Methane emissions did not correlate with the relative abundance of methanogens in the rumen measured by quantitative PCR, but there was a trend for higher methanogens concentration in the solid-associated population of D+ animals compared with D- animals. In contrast, PCR-denaturing gradient gel electrophoresis profiles of methanogens' methyl coenzyme-M reductase A gene showed a clear clustering in liquid-associated fractions for all three groups of donors but fewer differences in solid-associated fractions. These results show that the absence of protozoa may affect differently the methanogen community and methane emissions in wethers.
\end{abstract}

Key words: Rumen protozoa: Methanogens: Methane production: Fermentation characteristics

The capacity of domestic ruminants to feed on plant resources unsuitable for human consumption is a valuable asset within the current, sensitive context of increased world population, food insecurity and scarcity of resources. Notwithstanding, ruminant production has a large environmental impact with worldwide implications $^{(1)}$. A significant share of ruminants' environmental footprint is caused by enteric methane that represents about $25 \%$ of the annual anthropogenic methane emitted into the atmosphere ${ }^{(2)}$. Methane is the second most important greenhouse gas associated with human activity. It has a 100-year global warming potential that is twenty-five times greater than the equivalent amount of $\mathrm{CO}_{2}^{(3)}$; a figure that can increase to $20-40 \%$ if the direct and indirect effects of aerosols are included ${ }^{(4)}$.

Enteric methane is an end product of the anaerobic microbial fermentation of feeds generated within the gastrointestinal tract, particularly in the rumen, of ruminants. As a consequence, modulation of the rumen microbiota is a logical target that is being explored for reducing the emissions of methane by ruminants. For protozoa, a compilation of the available literature showed a relationship between methane production and the concentration of this group of micro-organisms in the rumen ${ }^{(5)}$. Protozoa are important $\mathrm{H}_{2}$ producers that play a key role in the interspecies hydrogen transfer and methane production within the rumen microbial ecosystem. Protozoa are ubiquitous, yet non-essential denizens of the rumen and their elimination, also termed defaunation, has been suggested as a way to mitigate methane emissions $^{(6,7)}$. The decrease in methane production in the absence of protozoa was observed both in vitro and in vivo. The average reduction is about $12 \%^{(5,7)}$. However, in many trials, no effect was reported ${ }^{(8-10)}$. The reasons for these dissimilar results are not well known. The length of the defaunation could have an influence, as methanogens have been reported to take a longer time than bacteria to adapt to changes in the rumen environment ${ }^{(11)}$. In addition, defaunation induces shifts in other microbial groups, including cellulolytic bacteria that might also alter rumen fermentation

Abbreviations: D, defaunated; D-, medium-term defaunation (6-12 weeks); D+, long-term defaunation (more than 2 years); D-centr, inocula obtained from centrifugation of rumen fluids from defaunated animals (6-12 weeks); D+centr, inocula obtained from centrifugation of rumen fluids from defaunated animals (more than 2 years); DGGE, denaturing gradient gel electrophoresis; DMD, DM degradation; F, faunated; Fcentr, inocula obtained from centrifugation of rumen fluids from faunated animals; VFA, volatile fatty acid.

*Corresponding author: D. P. Morgavi, fax +33473624273 , email diego.morgavi@clermont.inra.fr 
and methanogenesis ${ }^{(12-15)}$. Another aspect to be considered is the concentration of dissolved $\mathrm{H}_{2}$ in rumen fluid, a key driver influencing the methanogenesis and fermentation pathways in the rumen ${ }^{(16)}$. If the role of the protozoa as stimulators of methane production is mainly related to their $\mathrm{H}_{2}$-generating metabolism, then the lack of reduction in methane emissions observed in some cases in their absence could be due to increased activity of other rumen microbes that are also producers of $\mathrm{H}_{2}$. To better understand some of these mechanisms, in the present study, we examined the differences in both the fermentation characteristics and rumen methanogens in the presence and absence of protozoa. To this end, we used a combined in vitro and in vivo approach using conventional and defaunated wethers that were kept without protozoa for a short ( $<3$ months) or a long (more than 2 years) period of time.

\section{Experimental methods}

The experiment was conducted at the animal experimental facilities of the INRA's Herbivores Research Unit (St-Genès Champanelle, France). Procedures with animals were conducted in accordance with the guidelines for animal research of the French Ministry of Agriculture and applicable European guidelines and regulations for experimentation with animals (http://www2.vet-lyon.fr/ens/expa/acc_regl.html). The defaunation procedure was approved by the Auvergne regional ethics committee for animal experimentation (approval no. CE 20-08).

A total of six Texel wethers from the same genetic stock and fitted with rumen cannulae were used as donors of rumen fluid. Of the six animals, two had a regular, mixed protozoal population (faunated, F), while the other four animals had previously been defaunated by rumen emptying and washing following the method of Jouany \& Senaud ${ }^{(17)}$. At the time of experimentation, two of these animals had been kept defaunated for 6-12 weeks (medium-term defaunation, D-), while the other two had been kept in that state for more than 2 years (long-term defaunation, $\mathrm{D}+$ ). Wethers were fed a maintenance diet consisting of $700 \mathrm{~g}$ alfalfa pellet, $300 \mathrm{~g}$ cracked maize grain and $200 \mathrm{~g}$ prairie hay. Feeds were given twice daily at 08.00 and 16.00 hours, and access to water and mineral salt block supplement was unrestricted.

\section{Methane production and fermentation in vitro}

A first in vitro experiment was set up to assess the differences in fermentation and methane-producing capacity of rumen fluids originated from faunated wethers and wethers that had been kept defaunated for short or long periods of time. Whole rumen contents were collected before the morning feeding and strained through a polyester monofilament fabric $(250 \mu \mathrm{m}$ mesh aperture) to remove solids. Inocula for each treatment group were obtained by mixing equal parts of rumen fluid from both animals, and $10 \mathrm{ml}$ were immediately inoculated into $120 \mathrm{ml}$ vials containing $30 \mathrm{ml}$ of an anaerobic buffer solution ${ }^{(18)} \mathrm{kept}$ at $39^{\circ} \mathrm{C}$ and $300 \mathrm{mg}$ of ground ( $1 \mathrm{~mm}$ sieve) alfalfa hay ( $470 \mathrm{~g}$ neutral-detergent fibre, $156 \mathrm{~g}$ crude protein/kg DM) or maize grain (171 g neutral-detergent fibre, $78 \mathrm{~g}$ crude protein $/ \mathrm{kg} \mathrm{DM}$ ) as substrates. The vials were incubated anaerobically at $39^{\circ} \mathrm{C}$ for up to $24 \mathrm{~h}$. The vials without substrate were used as controls. At the end of the incubation period, gas production was measured with the aid of a pressure transducer and samples were collected for analysis of constituents by GC. The vial contents were centrifuged; the supernatants were processed for the analysis of soluble fermentation products and pellets were used for the estimation of DM degradation (DMD). For volatile fatty acids (VFA) and $\mathrm{NH}_{3}$ determination, $2 \mathrm{ml}$ supernatant was mixed with $0.2 \mathrm{ml} 5 \%$ $(\mathrm{v} / \mathrm{v})$ metaphosphoric acid in duplicate tubes and stored at $-20^{\circ} \mathrm{C}$ until analysis. The pellets were dried at $60^{\circ} \mathrm{C}$ for $48 \mathrm{~h}$ for DMD. The experiment was repeated twice, and within each experiment every treatment was assayed in triplicate.

In a second in vitro experiment, the effect of time after defaunation on methane production was further assayed by incorporating an 'on-the-spot' defaunation treatment. A treatment was done by low-speed centrifugation ( $500 \mathrm{~g}$ for $5 \mathrm{~min}$ ) of the faunated rumen fluid to get supernatants free of protozoa, which were then used as inocula (Fcentr). This technique allowed testing of only the effect of liquidassociated microbes on fermentation patterns, especially on methane production. Rumen fluids from defaunated animals were also centrifuged, and the supernatants (D-centr and $\mathrm{D}+$ centr) were used in the same way to compare their fermentation activities. Fermentations and measurements were carried out as described previously for the first experiment. All treatments were assayed in triplicate within an experiment, and the experimental design was repeated twice.

\section{Methane production and rumen fermentation in vivo}

In vivo methane production was measured in the same six animals used as donors for the in vitro experiments. The time elapsed between the in vitro and in vivo measurements was 6 weeks.

Methane production was determined during a $4 \mathrm{~d}$ period using the sulphur hexafluoride tracer technique ${ }^{(19)}$ as described by Martin et al. ${ }^{(20)}$. A calibrated permeation tube was introduced into the rumen of each sheep through the rumen cannulae 2 weeks before the initiation of sampling. The expected useful life, which is the length of time when sulphur hexafluoride release is constant, i.e. zero-order release of each permeation tubes, was calculated based on the diffusion rates of sulphur hexafluoride (1047 (SD 241) ng/min). As a precaution, only tubes that had a calculated useful life that was at least 8 weeks longer than the expected end of the experiment were used.

In addition to methane, rumen content samples were taken during two consecutive days $3 \mathrm{~h}$ after the morning feeding. Whole rumen contents were strained through a polyester monofilament fabric $(250 \mu \mathrm{m}$ mesh aperture), and the liquid filtrate was used for $\mathrm{pH}$, redox potential (Eh) and dissolved $\mathrm{H}_{2}$ measurements, which were done immediately after collection. Samples for VFA and $\mathrm{NH}_{3}$ were taken and stored as described for the in vitro experiments. 


\section{Archaeal community profile and sequencing}

The archaeal community present in faunated and defaunated wethers was characterised using quantitative PCR and PCRdenaturing gradient gel electrophoresis (DGGE). The rumen samples were taken $3 \mathrm{~h}$ after the morning feeding, and the whole rumen contents were strained through a polyester monofilament fabric $(250 \mu \mathrm{m}$ mesh aperture). Of the liquid filtrate, $1 \mathrm{ml}$ was transferred to $1.5 \mathrm{ml}$ microtubes and stored at $-80^{\circ} \mathrm{C}$ until processing. The solid retentate was washed twice with sterile, ice-cold $0 \cdot 1 \mathrm{M}$ - sodium phosphate buffer, $\mathrm{pH} 6.8$, and stored in tubes at $-80^{\circ} \mathrm{C}$ until processing.

Total DNA was extracted using the UltraClean Fecal DNA Kit from MoBio laboratories, Inc. (Solana Beach, CA, USA). The rumen liquid samples were thawed and centrifuged at $15000 \mathrm{~g}$, for $15 \mathrm{~min}$ at $4^{\circ} \mathrm{C}$. The supernatants $(750 \mu \mathrm{l})$ were decanted, and the pellets were processed following the kit manufacturer's protocol. Solid samples, approximately $300 \mathrm{mg}$, were kept frozen until the addition of guanidine isothiocyanate solution (Bead solution). DNA quantification was done by spectrophotometry.

Quantitative PCR for methanogens was carried out using primers targeting the methyl coenzyme-M reductase A ( $m c r A$ ) gene of the methanogenesis pathway as described by Denman et $a l^{(21)}$, and the total bacteria were quantified using primers targeting the $r r s$ gene ${ }^{(22,23)}$. The assays were run in triplicate using the SYBR Premix Ex Taq kit (Lonza, Levallois-Perret, France) on a StepOnePlus system (Applied Biosystems, Courtaboeuf, France). Negative controls without a DNA template were run with every assay to assess overall specificity. The abundance of methanogens was calculated relative to the abundance of total bacteria as the reference gene using the comparative $C_{\mathrm{T}}$ method $\left(2^{-\Delta C_{\mathrm{T}}}\right)^{(24,25)}$. The PCR amplification efficiency was checked as described previously $^{(13)}$ using standard curves, $10^{8}-10^{3}$ copies prepared from $m c r$ A or $r r s$ DNA fragments amplified from the genomic DNA of Methanobrevibacter smithii DSM861 and bacterial species, respectively. The slope and efficiency for $m c r \mathrm{~A}$ and rrs primers were -3.534 and $91.8 \%$ and -3.583 and $90.1 \%$, respectively. R2 in both cases was higher than 0.99. PCR efficiency with DNA samples was confirmed to be similar to that obtained with the standard curves.

For PCR-DGGE, the mcrA gene was also targeted using the following primers: forward, 5'-GGTGGTGTMGGATTCACACARTAYGCWACAGC-3' and reverse, 5'-TTCATTGCRTAGTTWGGRTAGTT- $3^{\prime(26)}$. The forward primer had a $40 \mathrm{bp}$ GC clamp added at its $5^{\prime}$-end ${ }^{(27)}$. The PCR mixture $(50 \mu l)$ contained $1 \times$ PCR buffer (Qiagen GmbH, Hilden Germany), $4.5 \mathrm{~mm}$ $\mathrm{MgCl}_{2}, 0.25 \mu \mathrm{M}$ of each primer, $200 \mu \mathrm{M}$ of each dNTP, $2.5 \mathrm{U}$ HotStar Taq polymerase (Qiagen $\mathrm{GmbH}$ ) and $50 \mathrm{ng}$ extracted DNA. The PCR conditions were those used by Luton et al. ${ }^{(26)}$ with a five-cycle slow ramp protocol to allow the extension of mismatched primers, except for the initial denaturation and final extension steps. The initial hot start denaturation was done for $15 \mathrm{~min}$ at $95^{\circ} \mathrm{C}$; the final extension step at $72^{\circ} \mathrm{C}$ was done for $30 \mathrm{~min}$ to eliminate artifactual double bands ${ }^{(28)}$

DGGE was performed on an $8 \%(\mathrm{w} / \mathrm{v})$ polyacrylamide gel in $0.5 \times$ Tris-acetate-EDTA buffer with a denaturant gradient of
$20-55 \%$ (100\% denaturant is $7 \mathrm{M}$-urea and $40 \%(\mathrm{v} / \mathrm{v})$ formamide). Electrophoresis was done for $5 \mathrm{~h}$ at $200 \mathrm{~V}$ at $60^{\circ} \mathrm{C}$. The gels were silver stained using a commercial kit (Bio-Rad Laboratories, Hercules, CA, USA), and the images were acquired using an optical density calibrated scanner (ImageScanner; GE Healthcare, Piscataway, NJ, USA) at a spatial resolution of $400 \mathrm{dpi}$. The images were analysed using GelCompar II version 4.0 package (Applied Maths, Kortrijk, Belgium). GelCompar II was used to normalise and compare all the DGGE patterns using hierarchical clustering to join similar patterns into groups ${ }^{(29)}$. To this end, all the images of DGGE gels were matched using the internal control sample, and the bands were quantified after a local background subtraction. A tolerance in the band position of $1 \%$ was applied. The similarity among patterns was calculated with the Pearson productmoment correlation coefficient, recommended for the analysis of this type of profiles ${ }^{(30)}$, and the clustering was done using the unweighted pair-group method with arithmetic averages.

Selected bands from DGGE gels were excised using disposable pipette tips, suspended in $20 \mu$ l of sterile distilled water and stored overnight at $4^{\circ} \mathrm{C}$. Eluted DNA was re-amplified using the same primers and run on a DGGE gel to check for the presence and purity of the desired band. In the case that more than one band was observed in the re-amplified product, the process was repeated until a single band was present. PCR products were cloned into Escherichia coli TOP10 Chemically Competent cell using a $\mathrm{pCR}^{\circledR} 4-\mathrm{TOPO}^{\circledR}$ vector (Invitrogen, Carlsbad, CA, USA) according to the manufacturer's instructions. DNA from randomly picked clones was amplified using the same primers and PCR conditions as described earlier. PCR products were purified with QIAquick PCR purification Kit (Qiagen $\mathrm{GmbH}$ ) and sequenced. The absence of chimeras in the sequences was checked using the program CHECK-CHIMERA $^{(31)}$. The sequences were subjected to blast searches (BLAST, http://www.ncbi.nlm.nih.gov/BLAST).

\section{Analytical procedures}

The presence of protozoa and their numbers were checked regularly throughout the length of the experimental period. Strained rumen fluid samples were mixed with a methyl green formalin solution $^{(32)}$ in a 1:1 ratio and stored at room temperature in the dark until used for protozoal counting. Samples were diluted in a methyl green-formalin solution if necessary, and enumeration was done using a Jessen counting chamber.

VFA were analysed by GC using a wall-coated open-tubular fused-silica column $(0 \cdot 25 \mathrm{~mm}$ inner diameter $\times 25 \mathrm{~m})$ coated with crude protein-wax 58 (FFAP)-CB (Varian BV, Middelburg, The Netherlands) ${ }^{(33)}$. $\mathrm{NH}_{3}$ was measured by colorimetry following the method of Weatherburn ${ }^{(34)}$ and using a Technicon autoanalyser II system as described by Davies \& Taylor ${ }^{(35)}$. Fermentation gases were analysed by GC as described ${ }^{(36)}$. Individual gas molar concentration was calibrated using a certified standard (relative accuracy of 2\%, Alphagaz no. 073562.00). Dissolved $\mathrm{H}_{2}$ in the rumen was extracted as described by Robinson et al. ${ }^{(37)}$ and analysed as described previously.

Data were statistically analysed by one-way ANOVA using the Statistical Analysis System software package, version 9 
(SAS Institute, Inc., Cary, NC, USA). For in vitro experiments, the MIXED procedures were used. The fermentation variables were analysed with a model that included protozoal populations as a fixed effect and experimental run (replication in time) as a random effect. Differences among means were tested using the PDIFF option. In vivo data were analysed using a contrast statement to compare faunated $v$. defaunated and medium- $v$. long-term defaunation. Significance was declared at the 5\% probability level, and trends were discussed at the 10 and $15 \%$ probability level for the in vitro and in vivo data, respectively.

\section{Results}

Experiments were performed to evaluate the changes induced by the absence of protozoa on rumen fermentation characteristics and rumen methanogens. Measures were taken in vitro and in vivo using wethers with (conventional) or without protozoa (defaunated) as part of the rumen microbiota. The defaunated donor animals remained free of protozoa throughout the sampling period. Faunated donor animals had a mean population of $3.8 \times 10^{6} / \mathrm{ml}$ composed of 84 and $11 \%$ small and large $(\geq 100 \mu \mathrm{m})$ entodiniomorphs, respectively, and $1.2 \%$ Isotricha and $2.9 \%$ Dasytricha.

\section{In vitro experiments}

In the first experiment, the fermentation characteristics of the rumen fluid from faunated animals (F) were compared with the rumen fluid from long-term (D+) and medium-term defaunated animals (D-; Table 1). Differences observed among inocula depended on the nature of the substrate that was fermented. However, methane production was the same for all inocula independently of the substrate. Alfalfa hay, rich in structural carbohydrates, had logically a higher acetate: propionate ratio and lower DMD than the maize grain substrate. D+ and F inocula had similar degrading capabilities, whereas D- was the least active inoculum. The absence of protozoa was associated with an increase in the proportion of acetate $(P<0.05)$ and a decrease in butyrate $(P<0.10)$ and branched VFA $(P<0 \cdot 05)$. Both defaunated inocula also presented a lower production of $\mathrm{NH}_{3}$ than faunated inoculum $(P<0.05)$, which together with the lower production of branched VFA indicates a decrease in the amount of protein degraded.

The starch-containing maize grain stimulated, as expected, the production of propionate and decreased that of acetate in all inocula. For this substrate, there were no differences between $\mathrm{D}+$ and $\mathrm{F}$ inocula in DMD or other indicators of the fermentation process except for a lower production of gas and a higher proportion of branched VFA $(P<0.05)$ in the presence of protozoa. Similarly to alfalfa hay, the D - inoculum was less capable of degrading the maize grain substrate compared with $\mathrm{D}+$ and $\mathrm{F}$ inocula. In contrast, total VFA production did not differ from other treatments $(P>0 \cdot 10)$. The percentage of propionate and $\mathrm{NH}_{3}$ production was also low in $\mathrm{D}-$ inoculum compared with $\mathrm{D}+$ and $\mathrm{F}$ inocula, while acetate increased proportionally $(P<0.05)$.

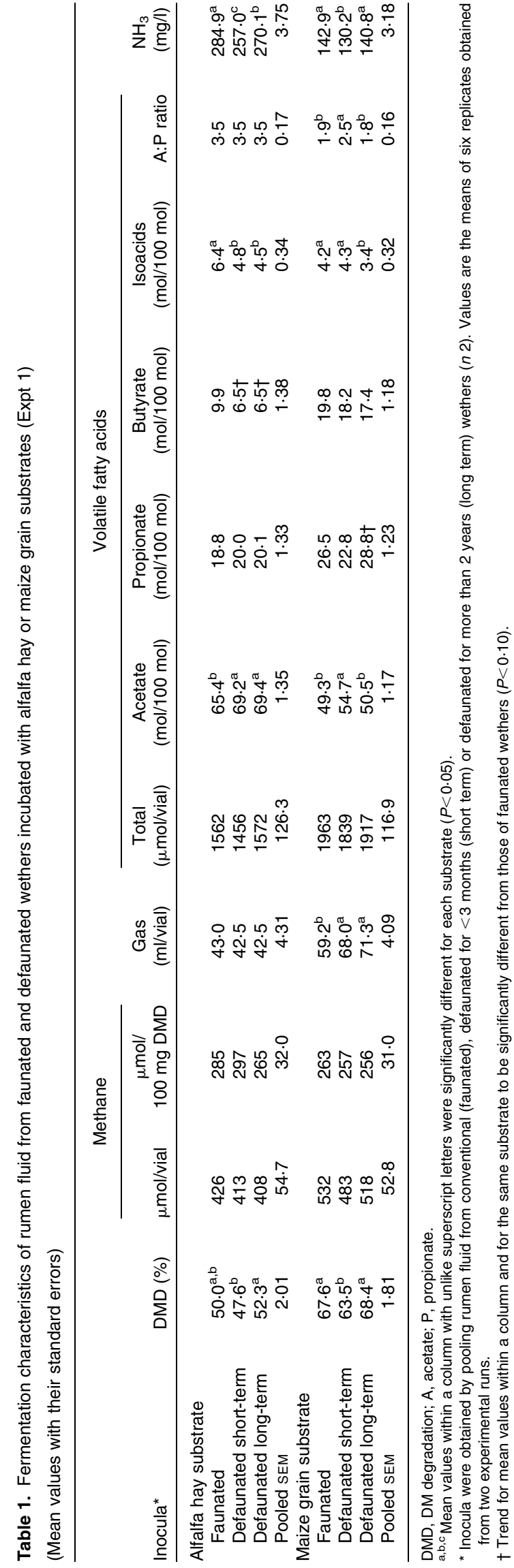


The recovery of hydrogen was estimated from the amount of acetate, propionate, butyrate and methane formed according to Demeyer ${ }^{(38)}$. It was about 88 and $97 \%$ for alfalfa hay and maize grain substrates (data not shown), respectively, without marked differences between inocula.

In the second experiment, the extent of time elapsed after defaunation was further assayed with three types of protozoa-free rumen fluids. Donor animals were the same as in Expt 1, but the rumen fluids from faunated and defaunated animals were freed from protozoa by the same low-speed centrifugation treatment to compare the activity of the following inocula: Fcentr, D-centr, D+centr (see the Materials and methods section for details). In this experiment, methane production increased with time passed since the defaunation was performed, in particular for $\mathrm{D}+$ centr that differed from $\mathrm{D}-$ centr and Fcentr $(P<0.05$, Table 2$)$. D + centr produced 18 and $11 \%$ more methane than Fcentr for alfalfa hay and the maize grain substrates, respectively. For maize grain substrate, D-centr produced the highest volume of methane per unit of DMD $(P<0 \cdot 05)$. The other main difference observed in the fermentation characteristics of these inocula was that there was a shift towards more production of acetate at the expense of propionate with increasing defaunation lengths, which resulted in higher acetate:propionate ratios $(P<0.05)$. The differences in acetate were significant $(P<0.05)$ between $\mathrm{D}+$ centr and Fcentr. The recovery of hydrogen for this experiment was about 90 and 105\% for alfalfa hay and maize grain substrates, respectively (data not shown). D-centr rumen fluid always had the lowest recovery rate and performed less well than the others without any apparent reason, as donor animals ate the same amount of feed and were clinically no different from other donors.

Centrifugation in addition to removal of protozoa in faunated rumen fluid also eliminated small feed particles and their attached microbes. The process produced changes in the VFA profile of Fcentr, which were in agreement with the absence of protozoa, but it also reduced the overall fermentation capacity of the rumen fluid inoculum, i.e. lower DMD and lower production of methane and $\mathrm{NH}_{3}$. Centrifugation also decreased DMD and total VFA production in D+centr compared with the results shown in Table 1 for the experiment without centrifugation. However, the decrement was not as marked and in the particular case of methane no effect was observed. These results indicate that the methanogenic activity in $\mathrm{F}$ and also in $\mathrm{D}-$ was distributed both in the liquid and small particles subfractions of the rumen fluid inocula, but it was predominantly found in the liquid subfraction in $\mathrm{D}+$.

\section{Rumen fermentation and methane production in vivo}

Table 3 shows the rumen fermentation characteristics and methane production of wethers used as donors of rumen fluid. It has to be pointed out that these measures were taken as a complement of the in vitro experiments, given that the number of animals was not optimal to highlight statistical differences. Nevertheless, and in agreement with the in vitro data, faunated wethers had higher rumen $\mathrm{NH}_{3}$ concentration and higher butyrate proportion than defaunated

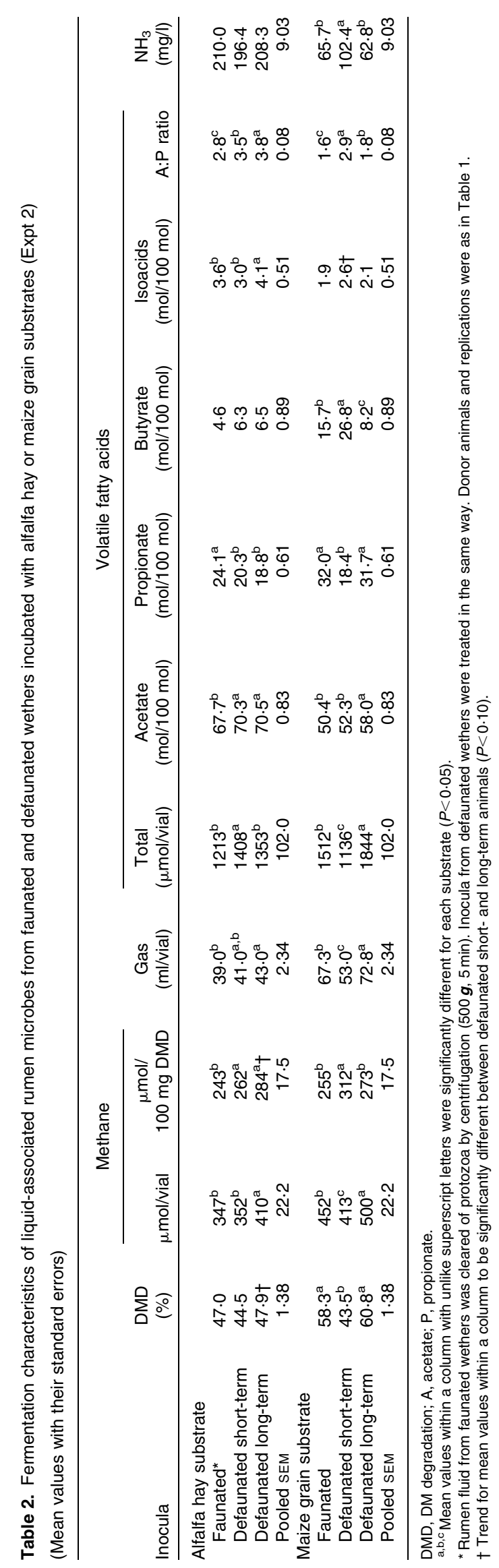


wethers $(P<0 \cdot 05)$. The lower fermentation activities in $\mathrm{D}-$ animals were also in accordance with the in vitro data. The daily production of methane in the three groups was quite contrasting, with the lowest emissions for $\mathrm{D}-$, about $35 \%$ less than $\mathrm{F}$, while no decrease was observed for $\mathrm{D}+$ animals compared with $\mathrm{F}$ animals. In particular, one $\mathrm{D}+$ animal had high methane emissions. The measures of dissolved $\mathrm{H}_{2}$ in the rumen showed a tendency for greater concentrations for $\mathrm{D}-$ wethers as opposed to $\mathrm{F}$ and $\mathrm{D}+$ wethers (Table 3; contrast $\mathrm{D}-v$. $\mathrm{D}+, P=0 \cdot 07$ ).

\section{Archaeal community}

The relative proportion of methanogens was higher in the solid-associated microbiota than in the liquid-associated microbiota $(P<0.05)$ independently of the treatment. For the liquid phase, $\mathrm{F}$ animals had a higher proportion of methanogens than D animals, although no statistical trends were evidenced. For the solid fraction, the proportion was higher for $\mathrm{D}+$, followed by $\mathrm{F}$ animals, and a lower proportion was observed in $\mathrm{D}-$ animals $(P=0 \cdot 102$; Table 4$)$.

The profiles of the methanogenic community obtained by PCR-DGGE and analysed by clustering of the whole densitometric curves revealed that D+ samples from the liquid phase were distinctly separated at the first node from the rest (Fig. 1). D- and F samples from the liquid phase also were placed in an independent cluster. In contrast, samples from the solid phase were grouped together, and the differences between the treatments were minor. A few bands were excised from the gels and sequenced to check whether the mcrA gene was correctly amplified. All retrieved bands belonged to the target gene with a sequence similarity that ranged from 85 to $93 \%$ with the closest cultured archaeal species. These were from the genus Methanobrevibacter represented by $M b b$. millerae, ruminantium and gottschalkii; Methanosphaera stadtmanae from the Methanobacteriaceae family and a clone distantly related to Methanolinea tarda; a newly described archaeon from the order Methanomicrobiales that was isolated from a sludge digestor ${ }^{(39)}$.

\section{Discussion}

The anti-methanogenic effects of many feed additives and dietary treatments have been directly or indirectly associated with their negative effect against protozoa. Some examples of these are supplements rich in medium-chain fatty acids, PUFA, saponins or the feed additive ionophore monen$\sin ^{(40-44)}$. Although the absence of protozoa from the rumen (fauna-free or defaunated animals) normally decreases methane emissions ${ }^{(5,7)}$, the reasons why in some other cases this effect was not observed are not well understood.

In the present in vitro experiments, changes in the molar proportion of VFA and $\mathrm{NH}_{3}$ observed in defaunated treatments, in particular for $\mathrm{D}-$ are in accordance with the literature ${ }^{(12,45)}$. Defaunation is also associated with a decreased degradability of feeds in the rumen ${ }^{(12)}$ as was the case for the D- inoculum. In contrast, the absence of protozoa did not reduce in vitro methane production as 
Table 4. Relative abundance of methanogens in the liquid and solid rumen phases of faunated and defaunated wethers used as donors of rumen fluid*

\begin{tabular}{lll}
\hline & $\begin{array}{l}\text { Liquid } \\
\text { phase }\end{array}$ & $\begin{array}{c}\text { Solid } \\
\text { phase }\end{array}$ \\
\hline Faunated & 0.41 & 0.61 \\
Defaunated short-term & 0.24 & 0.44 \\
Defaunated long-term & 0.26 & 0.82 \\
Pooled SEM & 0.150 & 0.113 \\
P† & 0.368 & 0.102
\end{tabular}

* Relative quantification assay using methanogens' methyl coenzyme-M reductase A gene and total bacteria rrs gene for normalisation †Treatment effect.

hypothesised from the previous in vivo results using similar conditions ${ }^{(46)}$. In the second in vitro experiment, rumen fluid inocula were centrifuged at low speed to eliminate protozoa in conventional (F) wethers in order to compare the effect of an 'on-the-spot' defaunation against the mediumand long-term defaunation treatments, in which the microbiota had the time to adapt to the absence of protozoa. The process also eliminated small feed particles and their associated microbes, non-retained by the $250 \mu \mathrm{m}$ mesh membrane that was used to separate the solid from the liquid rumen phase. Centrifugation reduced degradation of the substrate and production of VFA for all inocula. For the alfalfa hay substrate, the decreases were between 6 and $8.5 \%$, and for the starch-rich maize grain substrate, the decreases were up to $32.5 \%$, with D- being the most affected. This level of reduction is in agreement with the literature ${ }^{(47)}$. Compared with non-centrifugated inocula (Table 1) and particularly with hay as substrate, methane production decreased as expected as a consequence of the lower fermentation activity (D-centr and Fcentr) and the absence of protozoa (Fcentr). However, methane production was not affected in $\mathrm{D}+$ centr. This could be due to the absence of protozoa for a longer period of time in $\mathrm{D}+$ donors provoking changes in the planktonic microbial community that was more methanogenic than those of $\mathrm{D}-$ and $\mathrm{F}$ wethers.

In vivo measures allowed to make the association between fermentation characteristics and methane production observed in vitro to the actual rumen fermentation profiles and methane emissions for individual wethers. As stated previously in the results section, the number of animals used in vivo was not large enough to draw definitive conclusions, and the data should be regarded as complementary and enriching the interpretation of the totality of the results.

In accordance with the in vitro incubations of nonfractioned rumen fluid (Table 1), D+ wethers emitted a volume of methane that was similar to that of $\mathrm{F}$ animals. In contrast, the low volume of methane emitted by D- wethers was better associated with in vitro incubations performed with centrifuged rumen fluid (Table 2). Methane emission values were similar to those reported previously in our laboratory using the same sheep genotype and the same diet composition $^{(46)}$. In that study, the methane emission gap between faunated and defaunated animals was smaller, but the differences were significant as the design was different: five wethers went successively through defaunated, faunated and defaunated periods. The objective of the present study was different, and for practical reasons we were constrained to using a fewer number of animals meaning that the observed differences did not reach significant levels, i.e. $P=0 \cdot 17$ for contrast comparisons between $\mathrm{D}+$ and $\mathrm{D}-$.

Dissolved $\mathrm{H}_{2}$ in rumen liquid was the variable that negatively associated best with methane emissions, while other rumen parameters measured were in agreement with the differences expected between faunated and defaunated animals ${ }^{(12,48)}$. The concentration of $\mathrm{H}_{2}$ found in the rumen liquid after feeding were similar to those reported by Robinson et al. $^{(37)}$ using the same extraction method, but they were higher than the value of $1 \mu \mathrm{m}$ usually cited by other authors that was originally reported by Hungate ${ }^{(49)}$. However, the concentrations found were not as high as to inhibit microbial hydrogenase activity or to shift VFA

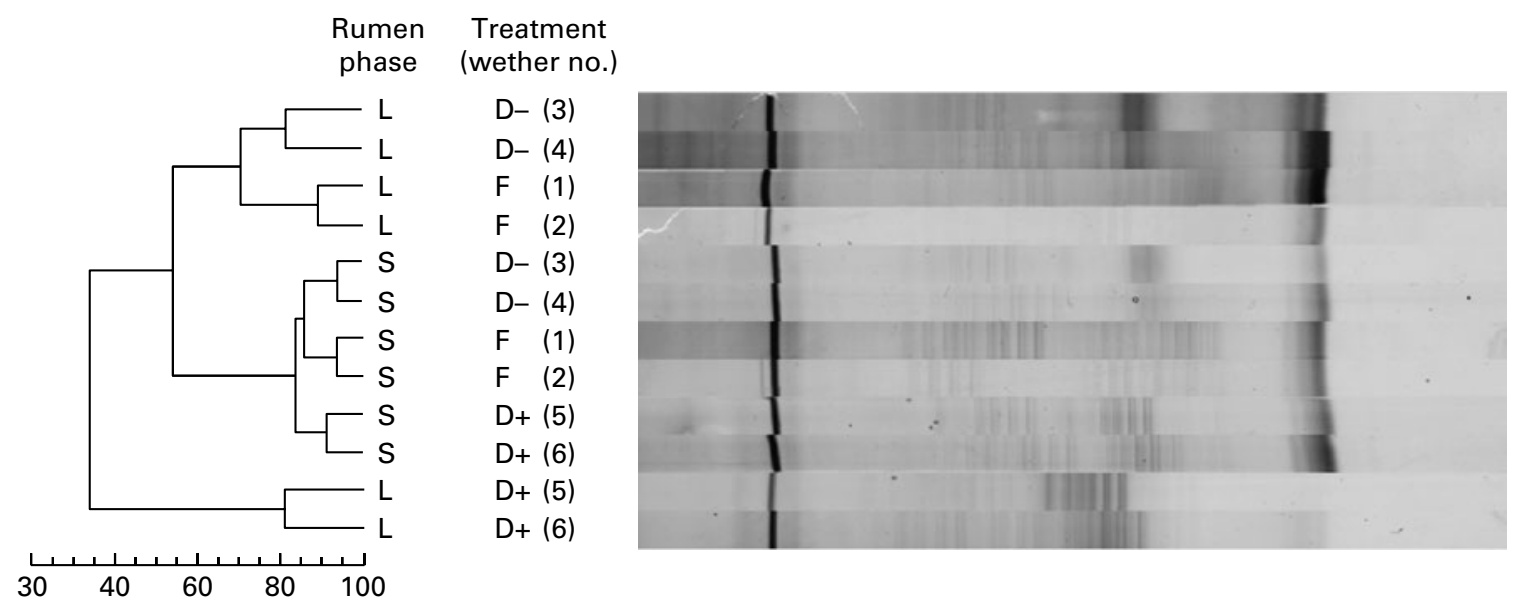

Fig. 1. Denaturing gradient gel electrophoresis profiles and unweighted pair-group method using arithmetic averages dendrogram generated from rumen methanogens (methyl coenzyme-M reductase $A$ gene). Samples are from the liquid (L) and solid (S) rumen phase of conventional (faunated; $F$ ), defaunated for $<3$ months $(\mathrm{D}-)$ or defaunated for more than 2 years $(\mathrm{D}+)$ wethers $(n 2)$. 
production into the more reduced propionate and butyrate products at the expense of acetate ${ }^{(50,51)}$. In the present study, the relationship between $\mathrm{H}_{2}$ concentration and methane was negative, which is in contrast to the data published by Hungate ${ }^{(49)}$ but partially agrees with a recent proposed model, in which a high concentration of dissolved $\mathrm{H}_{2}$ would result in less production of methane ${ }^{(16)}$. In contrast to that model, propionate production (a pathway that would be thermodynamically favoured with high $\mathrm{H}_{2}$ concentration) did not increase. The heterogeneity of the rumen environment could be a possible reason for the absence of variation in VFA proportions ${ }^{(16)}$. Higher $\mathrm{H}_{2}$ concentration coupled with lower methane production might suggest a lower efficiency to utilise $\mathrm{H}_{2}$ by the microbial community of $\mathrm{D}-$ animals compared with $\mathrm{F}$ and $\mathrm{D}+$ animals.

Taken together, the in vitro results are in agreement with the in vivo observations made on rumen contents of donors. The high methane-producing activity of D+ was not initially expected based on previously published information from our laboratory ${ }^{(46)}$. Methanogens were analysed by quantitative PCR and PCR-DGGE to appraise whether differences in methane production were correlated with the structure of the community. The proportion of methanogens relative to total bacteria was more evenly distributed between the liquid and solid rumen content phases in faunated wethers, while defaunated wethers had a lower proportion of methanogens associated with the liquid phase. This could be explained because protozoa are mainly associated with this fraction. Intracellular methanogens can represent as much as $1 \%$ of the protozoal biomass ${ }^{(52)}$ and up to $20 \%$ of rumen methanogens can be found attached to protozoa ${ }^{(53)}$. Analysis of the dissociation curves following quantitative PCR amplification revealed two peaks approximately at 81.5 and $87^{\circ} \mathrm{C}$ as those described by Denman et $a l^{(21)}$ for steers in Australia. In samples from $\mathrm{F}$ and $\mathrm{D}-$ animals, the $81.5^{\circ} \mathrm{C}$ peak, corresponding to the Methanobacteriaceae family ${ }^{(21)}$, was smaller than the one at $87^{\circ} \mathrm{C}$, while in $\mathrm{D}+$ animals, the difference was less accentuated. However, the dissociation curve of $\mathrm{D}+$ animals, particularly for samples from the liquid phase, had a third peak at $91^{\circ} \mathrm{C}$ that was as important as the $81.5^{\circ} \mathrm{C}$ peak (Fig. S1 of the supplementary material available online at http://www.journals.cambridge.org/bjn). The population(s) responsible for this peak was not identified in the present study, but the multiplicity of peaks in the dissociation curve of D+ was another indicator of the differences existing between these animals concerning the metabolism of methane.

The structure of the methanogen community characterised with PCR-DGGE targeted to the mcrA gene highlighted the differences among the liquid rumen fluids of donors, with clear changes in the archaeal community structure being observed in defaunated animals compared with animals harbouring protozoa. On the other hand, no effect of defaunation was observed on the solid phase. The primer set used could correctly identify faunated and long-term defaunated animals based on the different profiles present in the archaeal populations. We previously reported ${ }^{(54)}$ differences in microbial communities after PCR-DGGE using an archaeal primer set targeting the $16 \mathrm{~S}$ gene (0348aF and 0690aR, Achenbach and Woese (1995) as described in Watanabe et al. $^{(55)}$ ). However, sequencing of bands obtained from those gels did not produce any hit from the archaea but from bacterial domain. These 16S ribosomal DNA archaeal primers seem to be not specific; at least not for rumen samples and we do not recommend their use.

In conclusion, the absence of protozoa from the rumen microbiota did not systematically reduce methane production in rumens from wethers. Some of the reasons could be explained by changes in the community of methanogens, which following defaunation seem to develop slowly as evidenced by the differences between recent and long-term defaunated animals. Future work linking diversity and function of this community should be useful to improve our understanding of the mechanisms involved in methane production in the rumen.

\section{Acknowledgements}

The authors are grateful to D. Graviou and Y. Rochette for their technical assistance, M. Fabre and S. Alcouffe for the care of animals, and D. Durand and P. Gadyer for animal surgery. The present study was supported by the French National Institute of Agricultural Research (INRA). D. P. M. and M. J. R. conceived and designed the study and carried out the primary data analysis and experimental work. D. P. M. wrote the manuscript. C. M. and J.-P. J. contributed to the statistical analysis and discussion of the results. All authors revised the manuscript. There are no conflicts of interest

\section{References}

1. Steinfeld H, Gerber P, Wassenaar T, et al. (2006) Livestock's Long Shadow Environmental Issues and Options, pp. 390. Rome: FAO.

2. Lassey KR (2008) Livestock methane emission and its perspective in the global methane cycle. Aust J Exp Agric 48, 114-118.

3. Forster P, Ramaswamy V, Artaxo P, et al. (2007) Changes in atmospheric constituents and in radiative forcing. In Climate Change 2007: The Physical Science Basis. Contribution of Working Group I to the Fourth Assessment Report of the Intergovernmental Panel on Climate Change [S Solomon, D Qin, M Manning, Z Chen, M Marquis, KB Averyt, $\mathrm{M}$ Tignor and HL Miller, editors]. Cambridge/New York: Cambridge University Press.

4. Shindell DT, Faluvegi G, Koch DM, et al. (2009) Improved attribution of climate forcing to emissions. Science $\mathbf{3 2 6}$, 716-718.

5. Morgavi DP, Forano E, Martin C, et al. (2010) Microbial ecosystem and methanogenesis in ruminants. Animal $\mathbf{4}$, 1024-1036.

6. Boadi D, Benchaar C, Chiquette J, et al. (2004) Mitigation strategies to reduce enteric methane emissions from dairy cows: update review. Can J Anim Sci 84, 319-335.

7. Hegarty RS (1999) Reducing rumen methane emissions through elimination of rumen protozoa. Aust J Agric Res 50, 1321-1327. 
8. Machmüller A, Soliva CR \& Kreuzer M (2003) Effect of coconut oil and defaunation treatment on methanogenesis in sheep. Reprod Nutr Dev 43, 41-55.

9. Bird SH, Hegarty RS \& Woodgate R (2008) Persistence of defaunation effects on digestion and methane production in ewes. Aust J Exp Agric 48, 152-155.

10. Hegarty RS, Bird SH, Vanselow BA, et al. (2008) Effects of the absence of protozoa from birth or from weaning on the growth and methane production of lambs. Br J Nutr 100, 1220-1227.

11. Williams YJ, Popovski S, Rea SM, et al. (2009) A vaccine against rumen methanogens can alter the composition of archaeal populations. Appl Environ Microbiol 75, 1860-1866.

12. Eugène M, Archimède H \& Sauvant D (2004) Quantitative meta-analysis on the effects of defaunation of the rumen on growth, intake and digestion in ruminants. Livest Prod Sci 85, 81-97.

13. Mosoni P, Martin C, Forano E, et al. (2011) Long-term defaunation increases the abundance of cellulolytic ruminococci and methanogens but does not affect the bacterial and methanogen diversity in the rumen of sheep. J Anim Sci 89, 783-791

14. Williams AG \& Withers SE (1993) Changes in the rumen microbial population and its activities during the refaunation period after the reintroduction of ciliate protozoa into the rumen of defaunated sheep. Can J Microbiol 39, 61-69.

15. Ozutsumi Y, Tajima K, Takenaka A, et al. (2006) Real-time PCR detection of the effects of protozoa on rumen bacteria in cattle. Curr Microbiol 52, 158-162.

16. Janssen PH (2010) Influence of hydrogen on rumen methane formation and fermentation balances through microbial growth kinetics and fermentation thermodynamics. Anim Feed Sci Technol 160, 1-22.

17. Jouany JP \& Senaud J (1979) Defaunation of the sheep rumen. Ann Biol Anim Biochim Biophys 19, 619-624.

18. Goering HK \& VanSoest PJ (1970) Forage Fibre Analysis. Washington, DC: Agricultural Research Service, US Department of Agriculture.

19. Johnson K, Huyler M, Westberg H, et al. (1994) Measurement of methane emissions from ruminant livestock using a SF6 tracer technique. Environ Sci Technol 28, 359-362.

20. Martin C, Rouel J, Jouany JP, et al. (2008) Methane output and diet digestibility in response to feeding dairy cows crude linseed, extruded linseed, or linseed oil. J Anim Sci 86, 2642-2650.

21. Denman SE, Tomkins NW \& McSweeney CS (2007) Quantitation and diversity analysis of ruminal methanogenic populations in response to the antimethanogenic compound bromochloromethane. FEMS Microbiol Ecol 62, 313-322.

22. Edwards JE, Huws SA, Kim EJ, et al. (2007) Characterization of the dynamics of initial bacterial colonization of nonconserved forage in the bovine rumen. FEMS Microbiol Ecol 62, 323-335.

23. Edwards JE, Huws SA, Kim EJ, et al. (2008) Characterization of the dynamics of initial bacterial colonization of nonconserved forage in the bovine rumen. FEMS Microbiol Ecol 63, 141-142.

24. Denman SE \& McSweeney CS (2006) Development of a real-time PCR assay for monitoring anaerobic fungal and cellulolytic bacterial populations within the rumen. FEMS Microbiol Ecol 58, 572-582.

25. Schmittgen TD \& Livak KJ (2008) Analyzing real-time PCR data by the comparative C(T) method. Nat Protoc 3 , 1101-1108.
26. Luton PE, Wayne JM, Sharp RJ, et al. (2002) The mcrA gene as an alternative to $16 \mathrm{~S}$ rRNA in the phylogenetic analysis of methanogen populations in landfill. Microbiology $\mathbf{1 4 8}$, $3521-3530$.

27. Muyzer G, de Waal EC \& Uitterlinden AG (1993) Profiling of complex microbial populations by denaturing gradient gel electrophoresis analysis of polymerase chain reactionamplified genes coding for $16 \mathrm{~S}$ rRNA. Appl Environ Microbiol 59, 695-700.

28. Janse I, Bok J \& Zwart G (2004) A simple remedy against artifactual double bands in denaturing gradient gel electrophoresis. J Microbiol Methods 57, 279-281.

29. Fromin N, Hamelin J, Tarnawski S, et al. (2002) Statistical analysis of denaturing gel electrophoresis (DGE) fingerprinting patterns. Environ Microbiol 4, 634-643.

30. Savelkoul PH, Aarts HJ, de Haas J, et al. (1999) Amplifiedfragment length polymorphism analysis: the state of an art. J Clin Microbiol 37, 3083-3091.

31. Larsen N, Olsen GJ, Maidak BL, et al. (1993) The ribosomal database project. Nucleic Acids Res 21, 3021-3023.

32. Ogimoto K \& Imai S (1981) Atlas of Rumen Microbiology. Tokyo: Japan Scientific Societies Press.

33. Morgavi DP, Boudra H, Jouany JP, et al. (2003) Prevention of patulin toxicity on rumen microbial fermentation by SH-containing reducing agents. J Agric Food Chem 51, 6906-6910.

34. Weatherburn MW (1967) Phenol-hypochlorite reaction for determination of ammonia. Anal Chem 39, 971-974.

35. Davies AW \& Taylor K (1965) Application of the autoanalyser in a river authority laboratory. Symposium Technicon 294-300.

36. Broudiscou L-P, Papon Y \& Broudiscou A (1999) Effects of inorganic nitrogen and amino acids on the degradation of ammonia-treated barley straw and proteosynthesis in a continuous culture of rumen microbes. Anim Feed Sci Technol 77, 149-162.

37. Robinson JA, Strayer RF \& Tiedje JM (1981) Method for measuring dissolved hydrogen in anaerobic ecosystems: application to the rumen. Appl Environ Microbiol 41, 545-548.

38. Demeyer DI (1991) Quantitative aspects of microbial metabolism in the rumen and hindgut. In Rumen Microbial Metabolism and Ruminant Digestion, pp. 217-237 [JP Jouany, editor]. Versailles: INRA Editions.

39. Imachi H, Sakai S, Sekiguchi $\mathrm{Y}$, et al. (2008) Methanolinea tarda gen. nov., sp. nov., sp. nov., a methane-producing archaeon isolated from a methanogenic digester sludge. Int J Syst Evol Microbiol 58, 294-301.

40. Beauchemin KA, McGinn SM, Benchaar C, et al. (2009) Crushed sunflower, flax, or canola seeds in lactating dairy cow diets: effects on methane production, rumen fermentation, and milk production. J. Dairy Sci 92, 2118-2127.

41. Machmüller A, Soliva CR \& Kreuzer M (2003) Methanesuppressing effect of myristic acid in sheep as affected by dietary calcium and forage proportion. Br J Nutr $\mathbf{9 0}$, 529-540.

42. Martin C, Ferlay A, Chilliard Y, et al. (2007) Rumen methanogenesis of dairy cows in response to increasing levels of dietary extruded linseeds. In Energy and Protein Metabolism and Nutrition, EAAP Publication, pp. 609-610 [I OrtiguesMarty, N Miraux and W Brand-Williams, editors]. Wageningen: Wageningen Academic Publishers.

43. Mao H-L, Wang J-K, Zhou Y-Y, et al. (2010) Effects of addition of tea saponins and soybean oil on methane production, fermentation and microbial population in the rumen of growing lambs. Lives Sci 129, 56-62. 
44. Guan H, Wittenberg KM, Ominski KH, et al. (2006) Efficacy of ionophores in cattle diets for mitigation of enteric methane. J Anim Sci 84, 1896-1906.

45. Ranilla MJ, Jouany JP \& Morgavi DP (2007) Methane production and substrate degradation by rumen microbial communities containing single protozoal species in vitro. Lett Appl Microbiol 45, 675-680.

46. Morgavi DP, Jouany JP \& Martin C (2008) Changes in methane emission and rumen fermentation parameters induced by refaunation in sheep. Aust J Exp Agric 48, 69-72.

47. Newbold CJ, Lassalas B \& Jouany JP (1995) The importance of methanogens associated with ciliate protozoa in ruminal methane production in vitro. Lett Appl Microbiol 21, 230-234.

48. Williams AG \& Coleman GS (1992) The Rumen Protozoa. New York, NY: Springer-Verlag New York Inc.

49. Hungate RE (1967) Hydrogen as an intermediate in the rumen fermentation. Arch Microbiol 59, 158-164.
50. van Nevel CJ \& Demeyer DI (1996) Control of rumen methanogenesis. Environ Monit Assess 42, 73-97.

51. Thauer RK, Jungermann K \& Decker K (1977) Energy conservation in chemotrophic anaerobic bacteria. Microbiol Mol Biol Rev 41, 100-180.

52. Finlay BJ, Esteban G, Clarke KJ, et al. (1994) Some rumen ciliates have endosymbiotic methanogens. FEMS Microbiol Lett 117, 157-162.

53. Stumm CK, Gijzen HJ \& Vogels GD (1982) Association of methanogenic bacteria with ovine rumen ciliates. $\mathrm{Br} \mathrm{J} \mathrm{Nutr}$ 47, 95-99.

54. Morgavi DP, Jouany JP, Martin C, et al. (2006) Archaeal community structure diversity in the rumen of faunated and defaunated sheep. Int Congr Ser 1293, 127-130.

55. Watanabe T, Asakawa S, Nakamura A, et al. (2004) DGGE method for analyzing $16 \mathrm{~S}$ rDNA of methanogenic archaeal community in paddy field soil. FEMS Microbiol Lett 232, $153-163$ 